\title{
A GENERAL COMPUTER PROGRAM FOR RADIOCARBON DATING LABORATORIES
}

\section{CECILIO GONZÁLEZ-GÓMEZ}

Laboratorio de Datación por Carbono-14, Universidad de Granada, Facultad de Ciencias, E-18071 Granada, Spain

\begin{abstract}
Radiocarbon dating laboratories deal with many types of data and calculations, which include information on received and dated samples, age calculations and storage of results, printed reports to submitters and graphs plotted from sample measurements. I describe a computer program, designed to run on any PC-compatible computer with a hard disk, that can handle all the functions of a conventional liquid scintillation counting radiocarbon dating laboratory.
\end{abstract}

\section{INTRODUCTION}

The program I describe here, designed for liquid scintillation counting (LSC) laboratories, has been tested for several years in the Radiocarbon Dating Laboratory of the University of Granada, Spain (González-Gómez et al. 1991; González-Gómez 1992). It consists of 17 related programs that are automatically interconnected under a single user interface. The total size of the program files is $c a$. 614 Kbytes; total size of data files depends mainly on the quantity of stored samples. (As an example, all the records related to 200 dated samples use $c a$. 1 Mbyte of hard-disk space.) It is compatible with CGA, EGA, VGA or SVGA graphics; all screens, except for graphs, are displayed in color. The program's operator can print or display any data from sample information stored in the database. User-friendly, the program offers detailed menus, instructions and warnings at every stage.

\section{PROGRAM FUNCTIONS AND OPTIONS}

\section{Main Menu}

The main menu, accessible from all subprograms, contains the following options: 1. Previous files; 2. Dated samples files; 3. Calculations; 4. Graphs; 6 . Lists of samples and data; 7. Sites and people files; 8. Printing records and documents; 9. Initialization of variables and files; D. Exit to DOS. By pressing the key corresponding to one of these items, the user calls up on screen a secondary menu with several new options.

\section{Previous Files}

This option gives access to previous records, consisting of data provided on a form sent by the submitter along with the sample. A new record can be completed at any time before the dating of the sample.

\section{Dated Samples Files}

When final age calculations are made using the program, a final record of the sample is automatically created, combining previously existing record data with the measurement data and intermediate calculation values used to generate an age BP.

\footnotetext{
${ }^{1}$ Present Address: Consejo Superior de Investigaciones Científicas and Departamento de Química Inorgánica Radioquímica, Facultad de Ciencias, Universidad de Granada, E-18071 Granada, Spain
} 


\section{Calculations}

The age calculation is programmed according to Stuiver and Polach (1977), and all the steps of the calculations are shown on the screen or printed in the calculation sheet.

\section{Sites and People Files}

When a previous record is created, a record of the site is automatically added to the "sites file", and a record of the submitter to the "people file".

\section{FinAL Note}

Because this is intended only as a short summary description of the program, interested readers are invited to write to the author for more detailed information.

\section{REFERENCES}

González-Gómez, C. 1992 University of Granada radiocarbon dates VI. Radiocarbon 34(1): 133-139.

González-Gómez, C. and Sánchez-Sánchez, P. 1991 University of Granada radiocarbon dates V. Radiocarbon
33(3): 367-373.

Stuiver, M. and Polach, H. 1977 Discussion: Reporting of ${ }^{14} \mathrm{C}$ data. Radiocarbon 19(3): 355-363. 